\title{
The main causes of prematurity and their very common associated disorders
}

Without any doubt, preterm birth is the most critical situation in perinatal medicine and poses a serious public health problem since there is an increasing number of varying unsolved dilemmas.

The most concerning disorders especially affect very low birth weight preterm infants who, in spite of representing only $1-2 \%$ of all births, account for $50 \%$ of neonatal mortality.

An extremely important aspect that should be taken into account is the need to know the causes that lead to prematurity, since this may help to adopt measures aimed at reducing it.

The major concern today is that, over the last 20 years, instead of decreasing, prematurity rate has been steadily increasing in many countries, even in the most developed ones. An example of this is found in the United States - which is probably the most important country in the world-where the rate of prematurity reaches about $12 \%$. This figure is considerably higher than that found in other countries, not only in those of Western Europe, but also in others with fewer resources.

Prematurity stems from several causes that arise in inappropriate and very challenging situations. This is due to the presence of many disorders that have a significant impact on preterm infants during their neonatal period, their first year of life and in the long term.

Social and biological factors play a major role in the increase of prematurity, and are probably the main cause. In the history of humanity, at least since the emergence of Homo sapiens (70 000 years ago), There are innumerable examples where the living conditions were closely related to the health of people.This persisted around the world as far back as thousands of years up to the present insofar as the living conditions of many populations did not improve. Consequently, the vicious circle of povertyprematurity-malnutrition-diseases-poverty, led to the perpetuation of biological disorders which persisted through generations while the quality of life of the most vulnerable ones did not improve. Therefore, these factors are the most important and also the most difficult to modify if living conditions are not improved.

It has also been shown that social problems like poverty result in unfavorable working conditions during pregnancy, which is strongly correlated to prematurity. Some published studies have reported that women who have jobs associated with physically demanding responsibilities, such as manual labor, working more than 10 hours a day and standing for several hours a day, are at the highest risk of a premature birth. Adolescent mothers (younger than 18 years old), whose frequency is markedly higher in countries with limited resources, are particularly at risk of having a premature birth.

There are several other disorders that occur in prematurity-related social, cultural and biological factors. Some of them are the short-stature of the mother and the pre-pregnancy maternal underweight, childbirth at a young ( $\leq 19$ years old) or an advanced maternal age $(\geq 35)$, smoking, alcohol and drug use, low maternal education (they frequently fail to finish primary school). Likewise, these factors also affect preterm infants, such as insufficient weight gain in the neonatal unit, bacterial infections, bronchopulmonary dysplasia, and other disorders or diseases.

Besides, there is no doubt that factors related to a low sociocultural level are frequently associated with a risk for long-term development among very low weight preterm infants, as a result of the interaction between prematurity and the socioeconomic status. There is evidence that in these populations, children's prognosis is more unfavorable and they have a higher deficit in neurosensory development and cognitive functions. The main problem encountered by these families is that those disorders may last for life. Children who grow up in poverty are highly likely to be exposed to inadequate environmental factors, such as maternal deprivation and high levels of family stress, leading to less stimulating cognitive experiences and, therefore, the results are not good.

The decline of health care is also one of the most important aspects to be taken into account. The lower the maternal education and social level, the fewer the possibilities of receiving good antenatal care. This significantly affects prematurity due to the absence or decrease of strategies and advice provided during pregnancy, actions which may increase the likelihood of successful results.

Moreover, we should consider that it is not possible to minimize the impact of these living conditions during the relatively short pregnancy 
time. Even so, it is important to emphasize that a first appointment before 16-20 weeks of pregnancy can favor the adoption of certain measures aimed at reducing the rate of preterm birth, especially in populations at risk.

Other aspects to consider are the history of maternal health and current pregnancy disorders, since both may increase prematurity rates. Among the main causes, the most important one is having had a previous preterm birth, being the most frequent, given that the possibility of having another preterm birth increases by $50 \%$. Other causes are miscarriages during the second trimester (miscarriage in the first trimester does not increase the risk), cervical incompetence, and interpregnancy intervals of less than 9 months (birth spacing). Ideally, women should wait at least 18 months between giving birth and getting pregnant again.

Moreover, there are other complications that significantly increase prematurity rates. Multiple pregnancy is the most significant complication given that there is an increased risk of preterm delivery in a twin pregnancy. Such increase began several years ago, when in vitro fertilization started being used among women who could not get pregnant.

Other less common causes, but which almost inevitably lead to preterm birth, are previous placenta, placental abruption, premature rupture of membranes with amnionitis, and repeated urinary tract infections.

Finally, we should not forget the iatrogenic actions of doctors when performing a cesarean section in the face of the threat of premature labor, without taking appropriate measures to prolong pregnancy. Obstetricians can take several adequate actions to accomplish this. At least, this approach could extend pregnancy by some more days.

Finally, I would like to highlight that, in spite of the major advances made in medical science over the years and continuing today, prematurity is still an unsolved global issue in health care.

José María Ceriani Cernadas Editor

http:/ / dx.doi.org/10.5546/ aap.2019.eng.210

To cite: Ceriani Cernadas JM. The main causes of prematurity and their very common associated disorders. Arch Argent Pediatr 2019;117(4):210211.

\section{REFERENCES}

- Ceriani Cernadas JM. Los desafíos y dilemas no resueltos de la prematuridad. Arch Argent Pediatr. 2014;112(1):2-3.

- Beauregard JL, Drews-Botsch C, Sales JM, Flanders WD, Kramer MR. Preterm Birth, Poverty, and Cognitive Development. Pediatrics. 2018;141(1):e20170509.

- Doyle LW, Cheong JLY, Burnett A, Roberts G, et al. Biological and Social Influences on Outcomes of Extreme-Preterm/ LowBirth Weight Adolescents. Pediatrics. 2015;136(6):e1513-20.

- Twilhaar ES, Wade RM, de Kieviet JF, van Goudoever JB, et al. Cognitive outcomes of children born extremely or very preterm since the 1990s and associated risk factors. A metaanalysis and meta-regression. JAMA Pediatr. 2018;172(4)361-7.

- Gire C, Resseguier N, Brévaut-Malaty V, Marret S, et al. Quality of life of extremely preterm school-age children without major handicap: a cross-sectional observational study. Arch Dis Child. 2019;104(4):333-9.

- JohnsonSB, Riis JL, Noble KG.State of the art review: poverty and the developing brain. Pediatrics. 2016;137(4):e20153075.

- Meller CH, Carducci ME, Ceriani Cernadas JM, Otaño L. Ruptura prematura de membranas en nacimientos de pretérmino. Arch Argent Pediatr. 2018;116(4):e575-81. 